\title{
An auditory fovea in the barn owl cochlea
}

\author{
Christine Köppl ${ }^{1}$, Otto Gleich ${ }^{1, *}$, Geoffrey A. Manley ${ }^{1}$ \\ ${ }^{1}$ Institut für Zoologie der Technischen Universität München, Lichtenbergstraße 4, W-8046 Garching, Germany
}

Accepted: 12 October 1992

\begin{abstract}
The distribution of frequencies along the basilar papilla of the barn owl ( Tyto alha) was studied by labelling small groups of primary auditory neurones of defined frequency response and tracing them to their peripheral innervation sites. The exact location of marked neurones was determined in cochlear wholemounts with the aid of a special surface preparation technique. The average basilar papilla length (in fixed, embedded specimens) was $10.74 \mathrm{~mm}$.

The resulting frequency map shows the basic vertebrate pattern with the lowest frequencies represented apically and increasingly higher frequencies mapped at progressively more basal locations. However, the length of basilar papilla devoted to different frequency ranges, i.e. the space per octave, varies dramatically in the barn owl. The lower frequencies (up to $2 \mathrm{kHz}$ ) show values between about 0.35 and $1 \mathrm{~mm} /$ octave, which are roughly equivalent to values reported for other birds. Above that, the space increases enormously, the highest octave $(5-10 \mathrm{kHz}$ ) covering about $6 \mathrm{~mm}$, or more than half of the length of the basilar papilla.

Such an overrepresentation of a narrow, behaviourally very important frequency band is also seen in some bats, where it has been termed an acoustic or auditory fovea.
\end{abstract}

Key words: Hearing - Birds - Basilar papilla - Frequency map - Barn owl

\section{Introduction}

The common barn owl (Tyto alba) is a nocturnal bird that uses passive acoustic localization in hunting. When

* Present address: HNO Klinik der Universität Regensburg, FranzJosef-Strauß-Allec 11, W-8400 Regensburg. Germany

Abbreviations: CF. characteristic frequency; HRP, horseradish peroxidase: NA, Nucleus angularis; NM. Nucleus magnocellularis

Correxpondence 10: Dr. C. Köppl tested behaviourally, it is able to localize and strike prey purely on auditory cues (Payne 1971) and shows very sensitive hearing (Konishi 1973) and extreme accuracy of localization (Knudsen and Konishi 1979; Knudsen et al. 1979). The barn owl is therefore clearly an auditory specialist, providing the opportunity to study general principles of sound analysis in their most extreme form. Several prominent auditory specializations have already been demonstrated in this species: An intricate feather arrangement, the characteristic facial disc of the owl, serves to focus sound and, together with special skin flaps, provides additional directional cues (Payne 1971: Knudsen and Konishi 1979; Coles and Guppy 1988). Parallel pathways process timing and intensity information, respectively, in the auditory brainstem. They combine in the midbrain into a "space map" of neurones, forming the basis for the behaviorally-demonstrated localization accuracy (review in Konishi 1986). However, few studies have focussed on the hearing organ of the inner ear, the cochlea or basilar papilla.

The basilar papilla of the barn owl is by far the longest among birds (around $11 \mathrm{~mm}$; Schwartzkopff and Winter 1960; Smith et al. 1985; Fischer et al. 1988). While its apical part appears morphologically similar to the basilar papilla of typical birds, the more basal regions show obvious specializations. These include an unusual basilarmembrane thickening, so far not described in other birds, and an unusual sub-type of hair cell (Smith et al. 1985). In addition, the basal half of the papilla shows a remarkable constancy with respect to morphological parameters that are generally believed to influence its micromechanical properties, e.g. the height of the hair-cell stereovillar bundles (Fischer et al. 1988). Assuming the direction of frequency mapping along the barn owl basilar papilla is the same as in other birds (Manley et al. 1987; Gleich 1989), the morphologically-unusual basal area suggests a specialization for high-frequency processing. This is also consistent with the behaviourally-demonstrated exquisite sensitivity of the barn owl at frequencies up to $10 \mathrm{kHz}$ (Konishi 1973) or about one octave higher than typical birds (reviews in Manley 1990; Dooling 1992). 
To correlate specialized inner-ear features with physiological properties and behavioral performance, however, it is essential to know where the different frequencies are processed in the basilar papilla. The aim of the present study was therefore to determine the frequency map of the barn owl cochlea. The most precise mapping data are obtained by intracellular labelling of single afferent neurones. This method, introduced by Liberman (1982), however, requires good access to the auditory ganglion or nerve, which is difficult to achieve in the barn owl. We therefore chose to use extracellular HRP-labelling of small groups of physiologically-characterized primary neurones via injections into the cochlear nuclei, a method first used by Vater et al. (1985).

\section{Material and methods}

Experiments were performed on 11 adult barn owls (Tyto alba guttata) from our own breeding colony. Animals were anaesthetized by an initia! intramuscular dose of $3 \mathrm{mg} / \mathrm{kg}$ Xylazine ("rompun" by Bayer), followed $10 \mathrm{~min}$ later by $4 \mathrm{mg} / \mathrm{kg}$ Ketamine ("Ketanest" by Parke-Davis). To maintain anaesthesia, combined doses of half the respective initial amounts were necessary at 30 to 120 min intervals. Occasionally, a supplementary Xylazine dose was substituted with a $1.5 \mathrm{mg} / \mathrm{kg}$ dose of diazepam ("Valium" by Roche). Anaesthesia was continuously monitored via the electrocardiogram and muscle activity recorded with two fine insect-needle electrodes in leg and wing muscles. The rectal temperature was kept constant at $39^{\circ} \mathrm{C}\left( \pm 0.5^{\circ}\right)$ with the aid of a heating blanket wrapped around the animal. The owl's head was fixed in a stereotaxic setup via a metal pin cemented to the skull.

Closed sound delivery systems, each containing a Beyer DT 770 earphone and a Brüel \& Kjaer $1 / 2$-inch microphone with probe tube extension, were inserted into both ear canals. Sound pressure levels were individually calibrated and corrected to the position of the probe tube end, which was about $10 \mathrm{~mm}$ from the eardrum.

A small opening was made in the skull lateral to the cerebellum and the surface of the cerebellar flocculus exposed by removing the overlying bone and brain membranes. Glass microelectrodes could then be introduced through the flocculus aiming at the cochlear nuclei. For dye-marking, fine glass micropipettes were broken to an external tip diameter between 7 and $18 \mu \mathrm{m}$ (mean $13.7 \mu \mathrm{m}$ ) and filled with a solution of $30 \%$ horseradish peroxidase (HRP. Sigma No. P-8375) in $50 \mathrm{mM}$ Tris-buffer, $\mathrm{pH} 7.6$ and $150 \mathrm{mM} \mathrm{KCl}$. Electrode impedances ranged between 4 and $26 \mathrm{M} \Omega$ (mean $12.4 \mathrm{M} \Omega$ ). They permitted recordings from small groups of neurones, occasionally even from single cells.

Recording sites were identified according to stereotaxic coordinates, established in a prior experimental series of single-cell recordings using conventional glass microelectrodes, and according to known physiological criteria (Sullivan and Konishi 1984; Sullivan 1985; Carr and Konishi 1990). Within nucleus magnocellularis and nucleus angularis, the characteristic frequency $(C F)$, i.e. the frequency of stimulation producing a detectable response at the lowest sound pressure level, was determined audiovisually in regular depth intervals, usually $100 \mu \mathrm{m}$. At selected recording sites, a complete frequency-threshold curve was recorded under computer control. The frequency step size around CF was between 0.02 and 0.09 octaves, or up to 0.4 octaves for frequencies below $1 \mathrm{kHz}$. The CFs determined audiovisually or from the tuning curves did not differ systematically or significantly. Therefore, one case where the CF had only been determined audiovisually at an HRPmarked recording site was accepted for further analysis.

After recording the tuning curve, HRP was deposited iontophoretically. Positive DC current of 0.7 to $3.6 \mu \mathrm{A}$ (mean $1.6 \mu \mathrm{A}$ ) was normally applied for $10 \mathrm{~min}$ (range 5 and $19 \mathrm{~min}$ ). The resulting product of current and time varied between 6.4 and $40 \mu \mathrm{A} / \mathrm{min}$ (mean $15.3 \mu \mathrm{A} / \mathrm{min}$ ). In later experiments, up to 3 sites were marked on a given side of the brainstem, with the CFs differing between sites by at least one octave. In most cases, injections were performed on both sides of the brain.

Subsequently, the owls were either maintained under general anaesthesia for a further $22-32 \mathrm{~h}$ ( 5 animals) or allowed to recover and survive for $21-51 \mathrm{~h}$ ( 6 animals). In the latter cases, the exposed brain surface was covered with gelatine, the skin was treated with a local anaesthetic cream and sutured closed. During recovery and survival, the owls were housed singly. All animals were then deeply anaesthetized and perfused transcardially, first with $200-300 \mathrm{ml}$ of warm $0.9 \% \mathrm{NaCl}$ solution containing heparin, followed by the fixative (1 1 of $1 \%$ paraformaldehyde and $2.5 \%$ glutaraldehyde in $0.1 \mathrm{M}$ phosphate buffer, $\mathrm{pH}$ 7.4) and a rinse (1 1 of phosphate buffer).

Both cochleae were dissected free of the surrounding bone and isolated by cutting the VIIIth nerve. The tegmentum vasculosum was removed. The brain was also isolated, infiltrated with $30 \%$ sucrose and embedded in a gelatine-albumine mixture. Sections ( $75 \mu \mathrm{m}$ thick) of the relevant brainstem areas were then cut on a cryostat, with the plane of section being perpendicular to the brain's long axis and approximately in line with the upper beak. The unmounted sections and the cochlear wholemounts were processed together to visualize the HRP-label according to a protocol very similar to Liberman's (Liberman 1982), using diaminobenzidine (DAB) as the chromogen : $0.1 \mathrm{M}$ Tris-buffer, $\mathrm{pH}$ 7.6, for a minimum of $30 \mathrm{~min} ; 0.5 \% \mathrm{CoCl}_{2}$ and $1 \%$ dimethylsulfoxide (DMSO) in Trisbuffer for $60 \mathrm{~min}$ : Tris-buffer for $10 \mathrm{~min}$ : $0.1 \mathrm{M}$ phosphate buffer. $\mathrm{pH} 7.4$, for $10 \mathrm{~min}$; $0.05 \%$ DAB, $1 \%$ DMSO and approx. $0.01 \%$ $\mathrm{H}_{2} \mathrm{O}_{2}$ in phosphate buffer for $60 \mathrm{~min}$; and finally phosphate buffer for $30 \mathrm{~min}$. Brain sections were then mounted on slides and counterstained with neutral red. To estimate the size of HRP injection sites, diameter and area measurements were taken from camera-lucida drawings with the aid of a graphics tablet and associated computer software.

Cochleae were dehydrated and embedded in epoxy resin and the resulting blocks prepared for microscopic observation of the wholemount. The barn owl basilar papilla has a more complex threedimensional shape than that of typical birds. To view the papillar surface along its entire length, we cut 5 surfaces of different angles on the plastic block, each parallel and very close to the papilla and together following its curvature. A counter-surface of the same orientation was then cut opposite each surface. The cutting was done with the aid of a microtome and using glass knives, ensuring good control and smooth, highly transparent surfaces. The result was a multi-facetted block. When covered with a drop of immersion oil and placed between two coverslips (like a very thick section), each surface of the block could be viewed in turn at up to $400 \times$ magnification on an inverted microscope. Depending on how the cochlea was lying in the raw plastic block, opposite surfaces often ended up being laterally displaced. Observation was then possible under complete oil immersion in a specially-made holding device. By scanning the 5 surfaces sequentially and identifying unique points between adjacent surfaces, measurements of the papillar length and of the positions of marked neurones were made at $300 \times$ magnification.

\section{Results}

\section{Injection sites in the cochlear nuclei}

Birds have two cochlear nuclei, the nucleus magnocellularis (NM) and the nucleus angularis (NA). Due to the anatomical constraints of our recording approach, limiting possible electrode angles, only characteristic frequencies $(\mathrm{CFs})$ between about 3 and $5 \mathrm{kHz}$ were accessible in NM. In NA, however, CFs across the whole hear- 

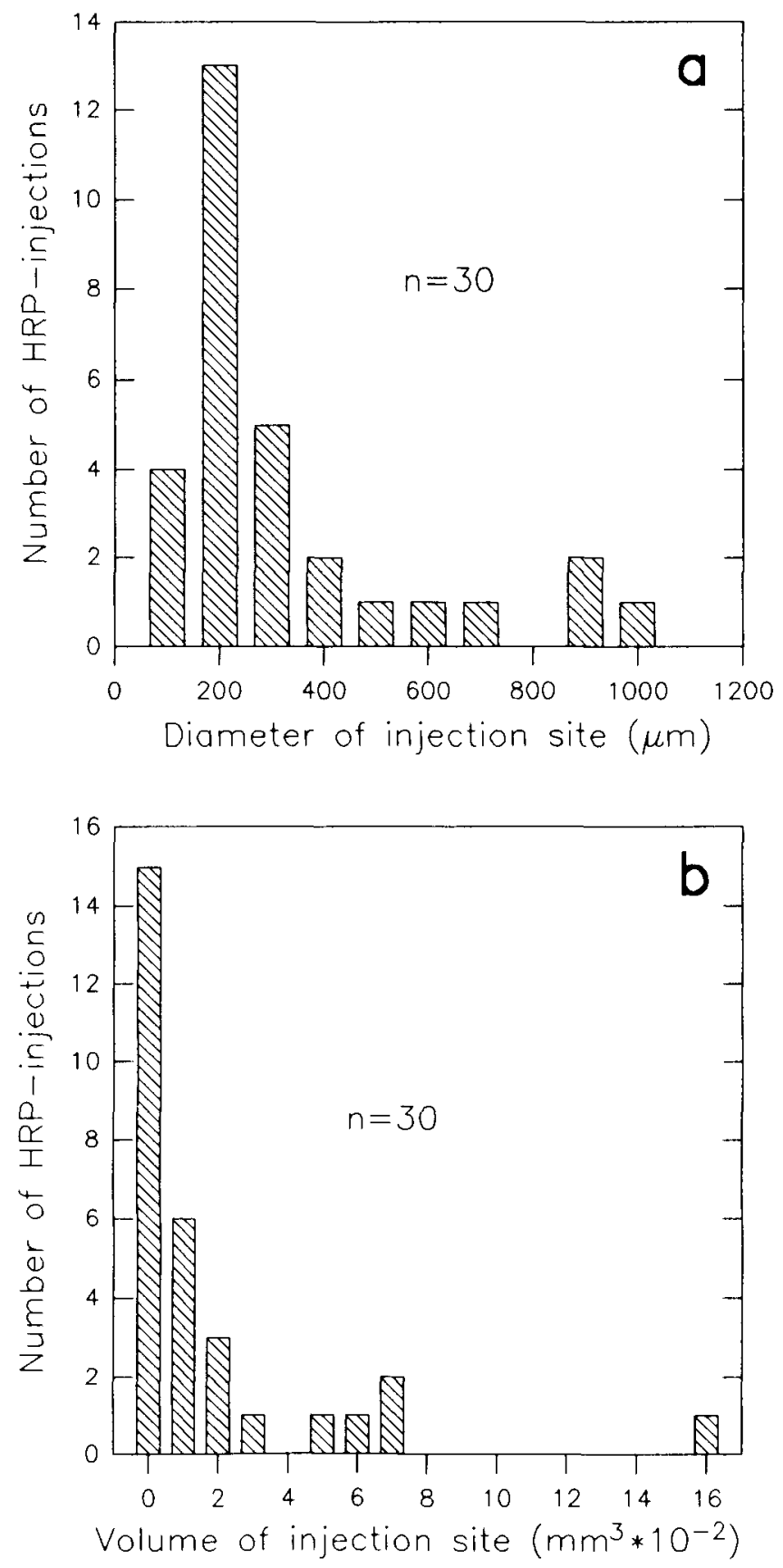

Fig. 1a, b. Distribution of the sizes of HRP-injection sites. a Maximal diameter of extracellular reaction product in frontal brain sections. b Volume of the extracellular reaction product summed across all sections

ing range could be reached, sometimes within a single electrode track. Consequently, 8 of a total of $30 \mathrm{HRP}$ injections were placed in NM and 22 in NA. CFs at the injection sites ranged from 0.25 to $9.6 \mathrm{kHz}$. The exact positions of injections sites and the primary collateral projection areas in the respective other cochlear nucleus, providing information about the tonotopic organization, will be the subject of a separate publication.

All injection sites were easily identified in the brain sections as areas containing varying amounts of extracellular HRP reaction product, surrounded by la- belled cell bodies and fibres. In cases of multiple injections into one side of the brainstem, the labelled sites were always non-contiguous and clearly separable. The extracellular reaction product was usually completely confined to the respective nucleus. In 2 cases, a small part of it extended beyond the cellular area, 2 further small injections were outside of, but immediately adjacent to, NA.

Injection size was estimated 1 . by measuring the diameter (maximal diameter encountered across sections) and 2 . by calculating the volume (as the sum of the products of area and section thickness), of the extracellular reaction product. The diameters varied between 75 and $1015 \mu \mathrm{m}$ (mean $335 \mu \mathrm{m}$; Fig. 1a), the volumes between 0.00025 and $0.161 \mathrm{~mm}^{3}$ (mean $0.0190 \mathrm{~mm}^{3}$; Fig. 1b). The total volume of NA is estimated to be approx. $1.5 \mathrm{~mm}^{3}$. that of NM approx. $2 \mathrm{~mm}^{3}$. Both diameter and volume of the injection sites correlated roughly with the total current applied. Typical examples of injection sites are shown in Fig. 2. The measured diameter was also used to estimate the frequency spread of each injection by projecting it onto the $\mathrm{CF}$-protocol of the corresponding electrode track and reading off the CF-range covered (Fig. 7a).

In all but two cases, marked fibres of primary ganglion cells could be seen emanating from the injection site and could be followed to the root of the VIIIth nerve. However, only 23 out of 30 injections showed labelled cochlear ganglion cells (see below). In cases of multiple injections into one side of the brainstem, the marked fibres resulting from different injection sites remained separable on their way to the periphery.

\section{Labelling pattern in the cochlea}

To identify marked primary neurones in the cochlear wholemounts, we used a surface preparation technique that allowed clear high-magnification views through the papillar surface (see Methods). To test the reliability of our method in determining the papillar length and the positions of marked neurones, most cochleae were measured twice, some a third time by a different person. Repeated length measurements of the same cochlea differed by between 0.02 and $1.7 \mathrm{~mm}$ (mean $0.53 \mathrm{~mm}$ ), the largest values probably including protocol errors. Repeated measurements of the position of individual entrance points of marked nerve fibres (see below) along the length of the papilla differed by between 0 and $5.9 \%$ of the total length (mean $1.0 \%$ ). For all values given in this paper, only the last measurement of each cochlea, carried out with the most experience, was used. The average papillar length (measured along its midline) was $10.74 \mathrm{~mm}( \pm 0.35 \mathrm{~mm}$ standard deviation, $n=16)$.

Marked cochlear ganglion neurones were found for 23 of the $30 \mathrm{HRP}$-injections. The sizes of the corresponding injection sites of cases with no peripheral labelling were all on the lower end of our spectrum. However, other injections of similar size were successful just as often. Thus, we cannot report a minimal injection size for success in peripheral labelling. Injection sites larger than 


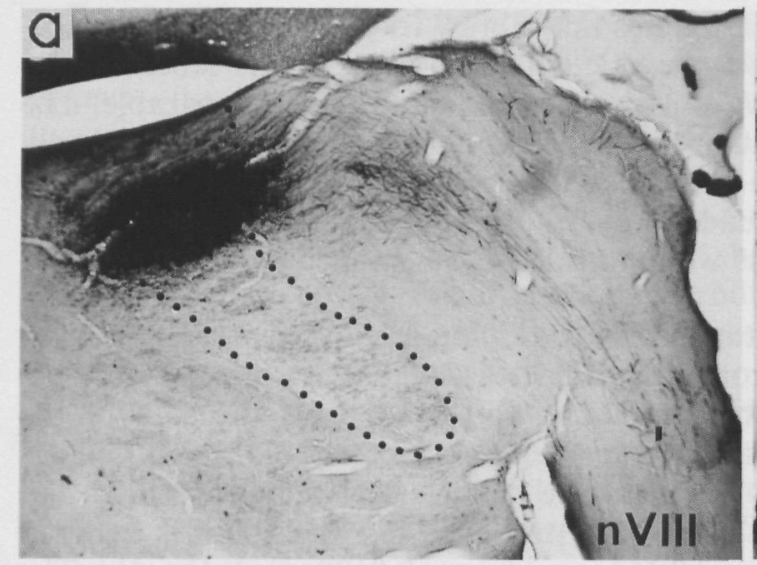

Fig. 2a-c. Photomicrographs of representative examples of injection sites, which led to peripherally-labelled neurones in the cochlear wholemount. Each panel shows part of a frontal brainstem section, with the cochlear nucleus outlined by a dotted border. Dorsal is always to the top, the midline to the left in a, to the right in $\mathbf{b}$ and c. Scale bar in b is $1 \mathrm{~mm}$ and applies to all 3 micrographs. a One
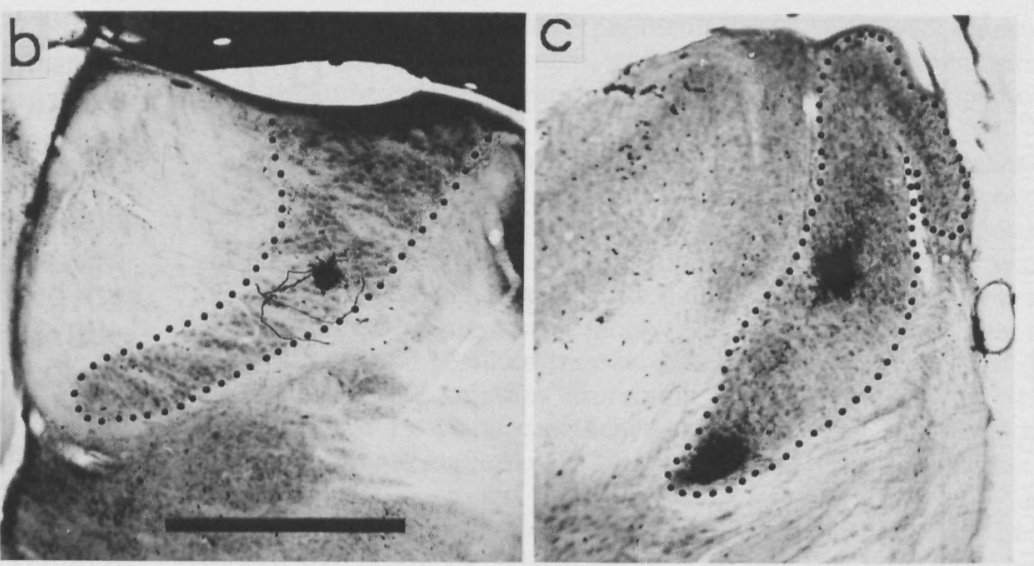

of the larger injections $\left(450 \mu \mathrm{m}\right.$ diameter, $0.07 \mathrm{~mm}^{3}$ volume) into NM. Stained fibres can be seen emanating from the injection site and travelling in the eighth nerve (nVIII). b A very localized injection into $\mathrm{NM}\left(150 \mu \mathrm{m}\right.$ diameter, $0.001 \mathrm{~mm}^{3}$ volume). c Two average-sized injections (200 and $250 \mu \mathrm{m}$ diameter, 0.0033 and $0.0066 \mathrm{~mm}^{3}$ volume) from a single electrode track through NA
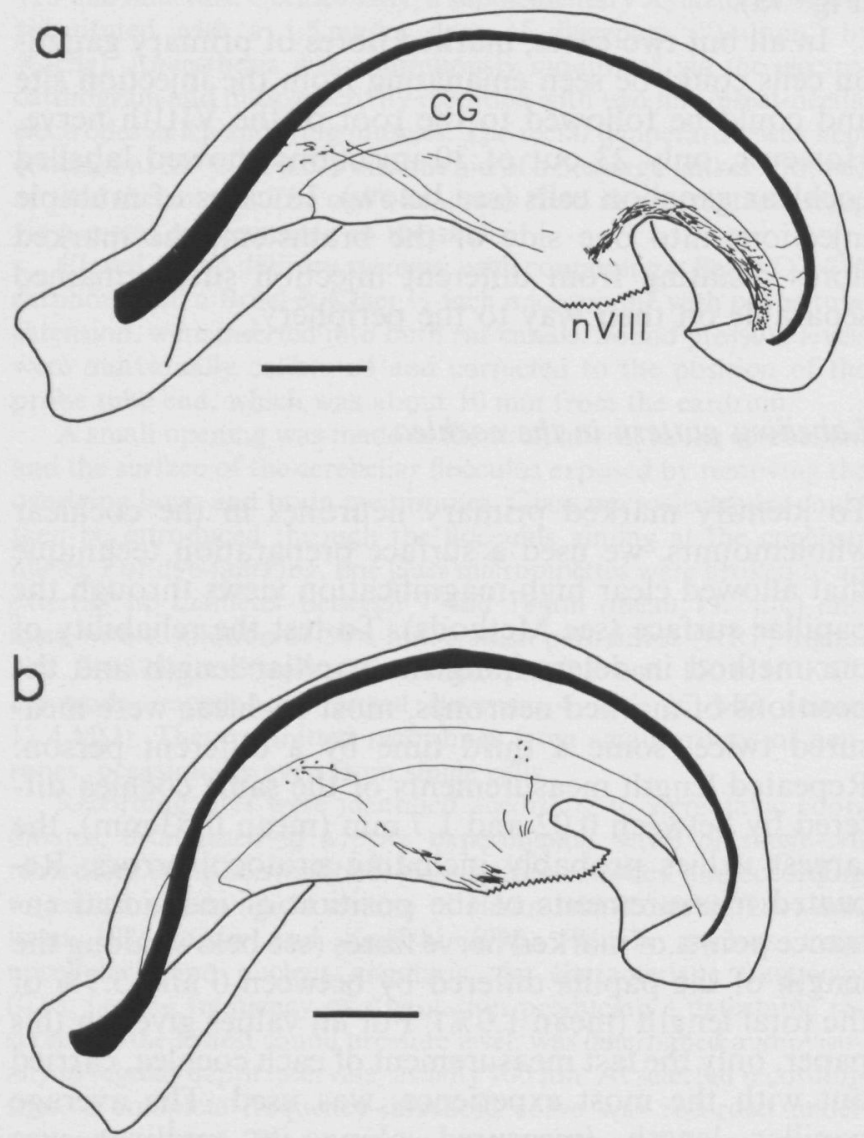

Fig. 3a, b. Schematic drawings of two cochlear wholemounts, as seen at low magnification. Apical is to the left, basal to the right, the cut end of the VIIIth nerve (nVIII) is indicated by a saw-toothed line. The basilar papilla is drawn as a solid black band, and the outline of the cochlear ganglion (CG) is indicated by thin lines. Scale bar $1 \mathrm{~mm}$. Two groups of stained primary neurons can be distinguished in each case, in a their CFs were $9.6 \mathrm{kHz}$ (for the group at the basal end) and $3.36 \mathrm{kHz}$, in b the CFs were $8.4 \mathrm{kHz}$ and $5.3 \mathrm{kHz}$

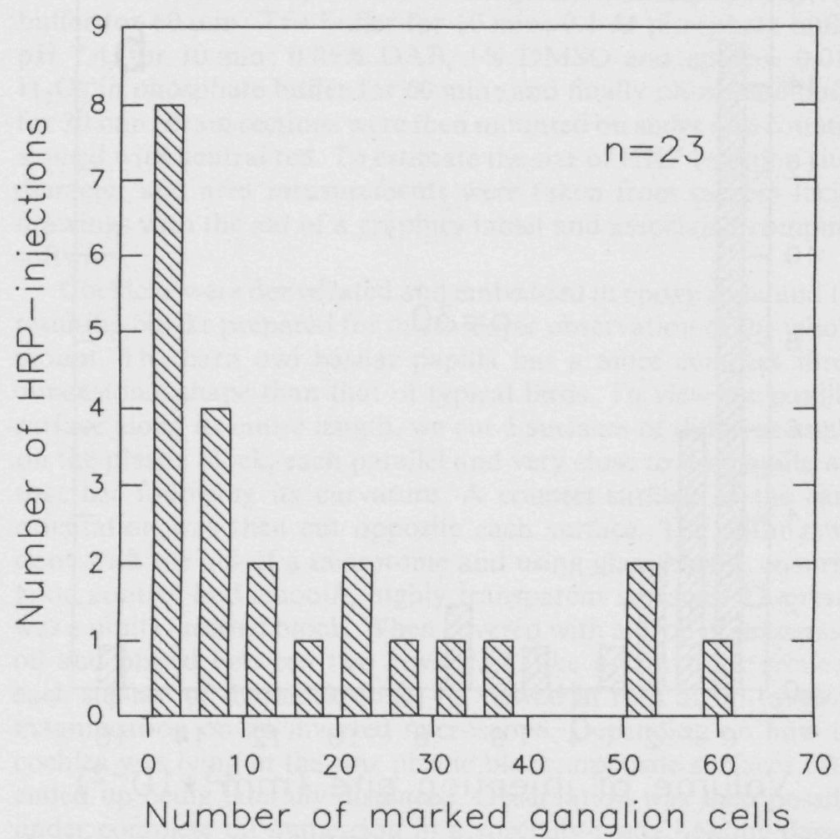

Fig. 4. Distribution of the numbers of marked cochlear ganglion cells found after each successful HRP-injection (bin width $=5$ cells). Injections that yielded no peripheral labelling have been omitted

about $400 \mu \mathrm{m}$ in diameter always yielded marked primary neurones. Travel distances from the injection site to the basilar papilla were estimated to be between 6 and $10 \mathrm{~mm}$.

As in the brain sections, labelled neurones resulting from different injections into one side of the brainstem formed non-contiguous and thus separable groups in the ganglion as well as in the nerve (examples in Fig. 3). If fewer labelled groups of neurones were found than injections had been made (4 ears), the CF of neurones found was allocated on the basis of their positions in the gangli- 


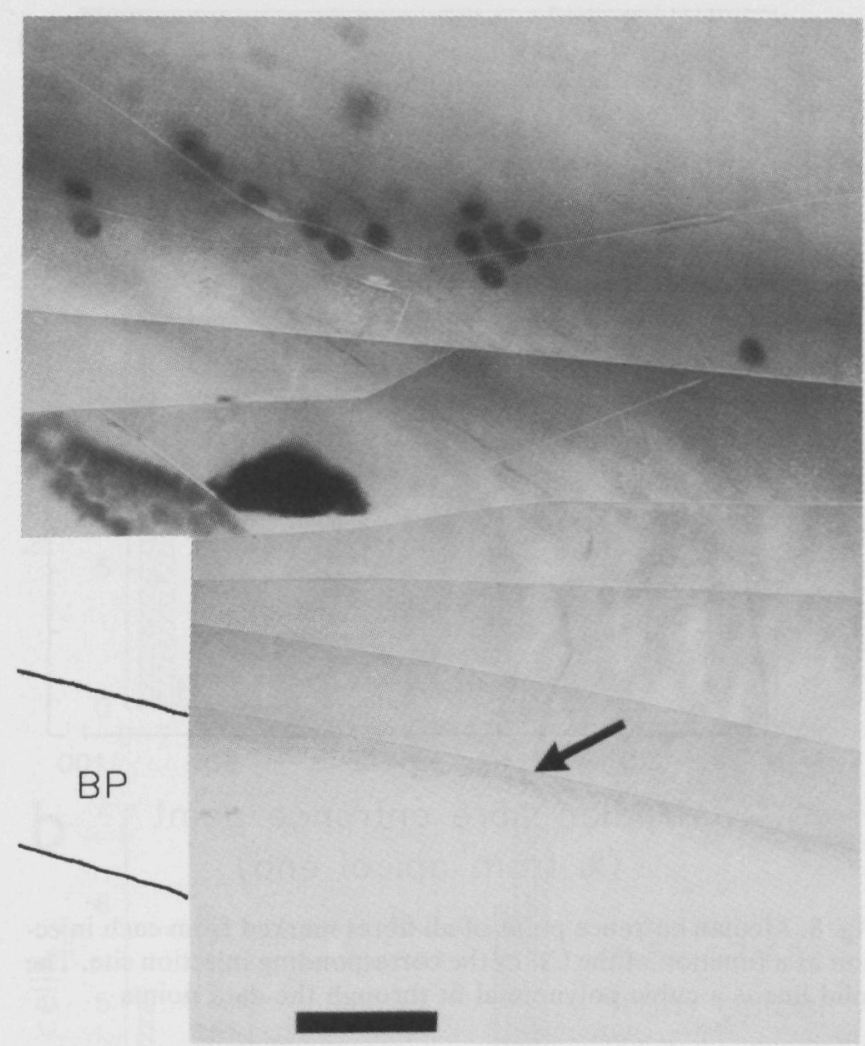

Fig. 5. Videomontage of a wholemount view of a group of labelled ganglion cells (at the top) with one marked fibre followed to its entrance point into the basilar papilla (arrow). The basilar papilla is not clearly discernable due to overexposure, therefore its neural and abneural borders are indicated on the left of the picture $(\mathrm{BP}=$ basilar papilla). Scale bar $100 \mu \mathrm{m}$

on, of their innervation sites in the basilar papilla and of the corresponding injection site compared to those values from unambiguous single-injection cases.

The number of ganglion cell bodies stained by a given successful injection varied between 1 and approx. 60 (mean 13; Fig. 4). No correlation was seen between the injection size and the number of marked primary neu- rones. The labelling was rarely homogeneously black, but more often weak, with a granular appearance in the cell body of cochlear ganglion cells and intermittent labelling of the axonal processes, especially the peripheral one running towards the papilla. In 17 cases (of 23), between 1 and 9 (51 in one exceptional case) marked fibres could be followed to the basilar papilla. However, the label mostly faded at the habenula (example in Fig. 5), rarely even before. Staining within the hair-cell region was only seen after the largest HRP-injections (example in Fig. 6). This appearance of label is not due to poor visibility in the wholemount, but was confirmed by sectioning some cochleae (10 $\mu \mathrm{m}$ section thickness).

\section{Position of marked neurones along the basilar papilla}

Peripheral to the ganglion, the nerve fibres form distinct fibre bundles which split into smaller bundles during their course towards the basilar papilla. We chose to accept all fibres that were marked beyond the last splitting point of these fibre bundles (i.e. within $100-250 \mu \mathrm{m}$ of the papilla) as cases of reliably-determined points of entry into the basilar papilla. However, since not all HRP-injections yielded primary neurones labelled so close to the basilar papilla, other methods of expressing the position of label were also employed. The position of marked ganglion cells along the basilar papilla, used in some similar studies on mammalian species (Vater et al. 1985; Müller 1991), was found not to be a good estimator of the innervation site. In the barn owl, the ganglion cells lie up to one $\mathrm{mm}$ away from the papilla. When correlated with the unambiguously-determined fibre entrance points, the ganglion cells were systematically shifted basally over the apical two thirds of the papillar length, the discrepancy becoming larger (up to $15 \%$ ) in approx. the apical fifth of papillar length. A better method of estimating the innervation sites of labelled ganglion cells was found by following the nerve branchlets radiating out from the ganglion towards the papilla and thus determining a possible range of termination sites. Although such an estimated range is of course broader when compared

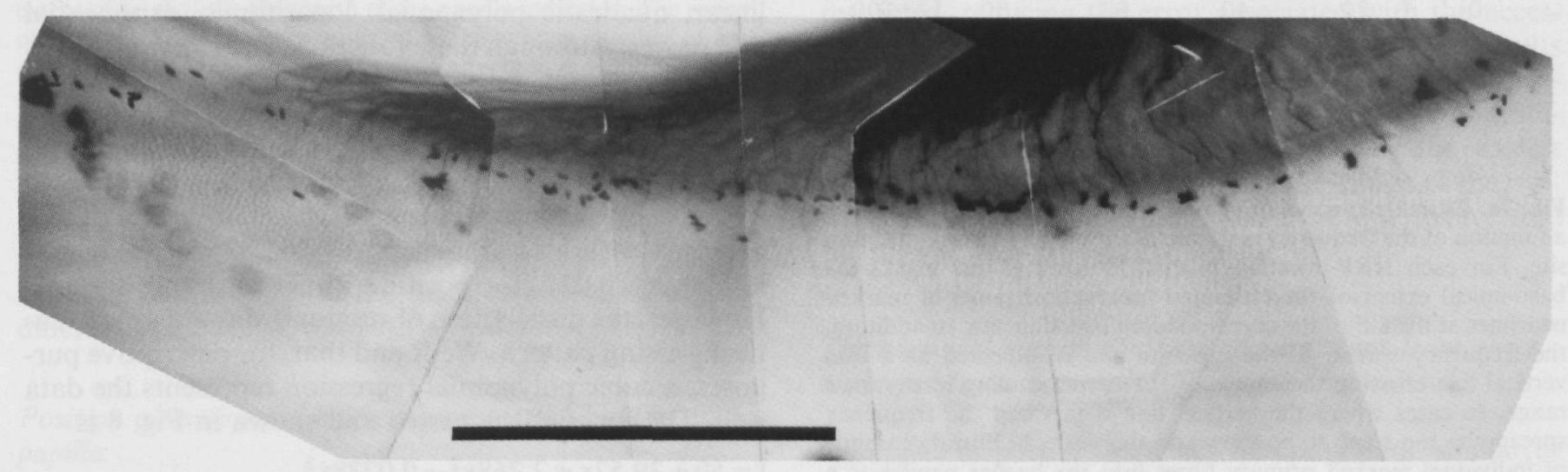

Fig. 6. Videomontage of a wholemount view onto the most apical $2 \mathrm{~mm}$ of papillar surface. Apical is to the left, neural to the top; scale bar $0.5 \mathrm{~mm}$. Numerous labelled fibres can be seen entering the basilar papilla and some can be followed a significant distance across the hair-cell area, which has a granular appearance 

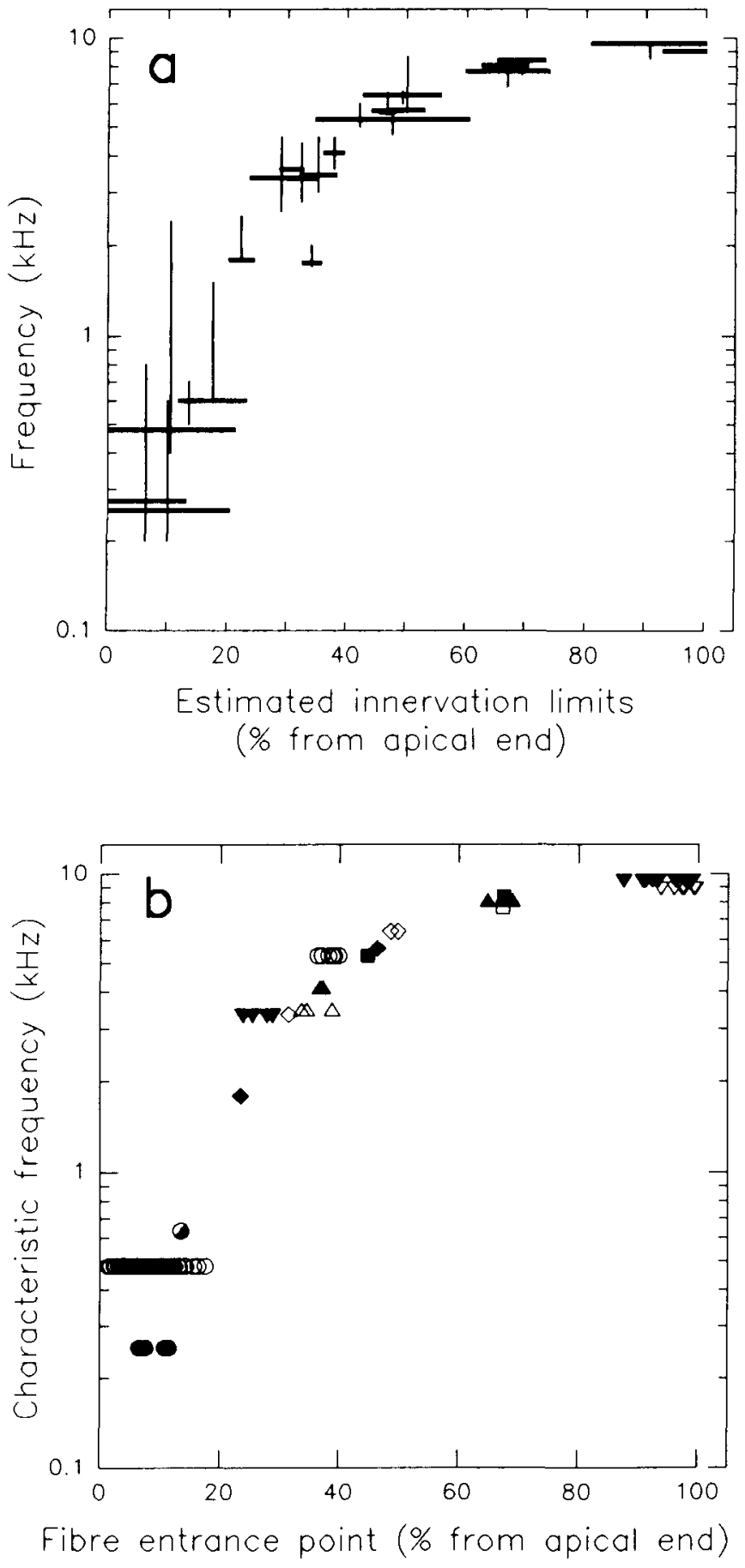

Fig. 7a. Estimated innervation ranges along the basilar papilla as a function of the frequency response at the corresponding injection site. For each HRP-injection, a thick horizontal line marks the baso-apical extent of the estimated innervation range of marked neurones at the CF of the corresponding injection site. In addition, the frequency spread of the injection site is indicated as a thin vertical line crossing the centre of the corresponding innervation range. In cases where the vertical line is missing, the frequency spread was too small to be shown on this scale. b. Entrance points of individual marked primary fibres into the basilar papilla as a function of the $\mathrm{CF}$ at the corresponding injection site. Entrance points for fibres from each individual ear are represented by the same symbol

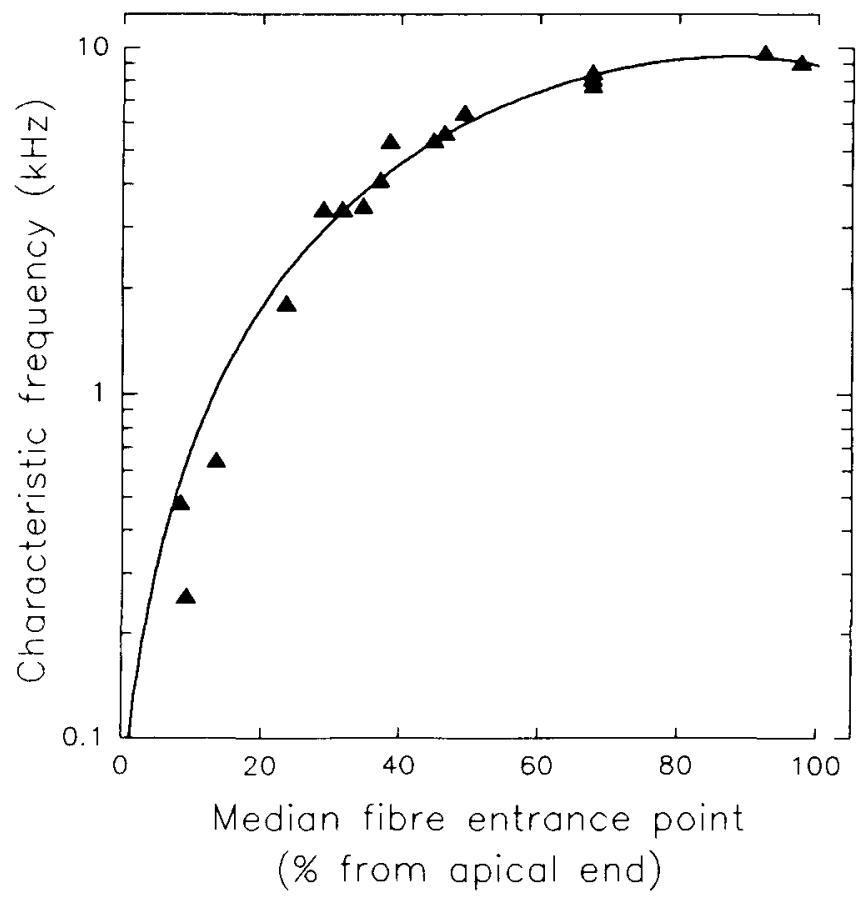

Fig. 8. Median entrance point of all fibres marked from each injection as a function of the CF of the corresponding injection site. The solid line is a cubic polynomial fit through the data points

to the range of fibres actually entering the papilla in the same case, it provides a reliable measure showing no systematic deviations.

Both measures of the position of label, the estimated innervation ranges and the positions of fibre entry into the basilar papilla are shown in Fig. 7 as a function of the CF recorded before HRP-injection. Neurones of the lowest frequencies terminated near the apical end, increasingly higher frequencies were represented progressively closer to the basal end.

In order to characterize this frequency distribution in a more detailed fashion, only the unambiguously-determined fibre entrance points were used. For each HRPinjection, the median fibre entrance point was determined (Fig. 8) and a regression analysis carried out with these values. The following functions were tested (assuming frequency as the dependent variable) and gave poor fits: linear, quadratic polynomial, logarithmic, exponential and power. Although these functions yielded high, statistically-significant correlation coefficients; all showed clear patterns in their distribution of residuals, indicating an unsatisfactory fit. In addition, a specific frequency mapping function suggested by Greenwood (1990) to fit a variety of cochleae was tested. The relative best fit was obtained with his parameters $\mathrm{A}=105.82$ (for frequency in $\mathrm{Hz}$ ), $\mathrm{a}=0.021$ (for position in percent) and $\mathrm{k}=0.82$. However, the distribution of residuals showed a systematically-rising pattern. We found that, for descriptive purposes, a cubic polynomial regression represents the data well. The function suggested and shown in Fig. 8 is

$\mathrm{f}=50+39.57 \mathrm{x}+2.768 \mathrm{x}^{2}-0.0228 \mathrm{x}^{3}$

where $\mathrm{f}=$ frequency in $\mathrm{Hz}, \mathrm{x}=$ position in $\%$ from apical end. To achieve a realistic function, the $y$ intercept, i.e. 

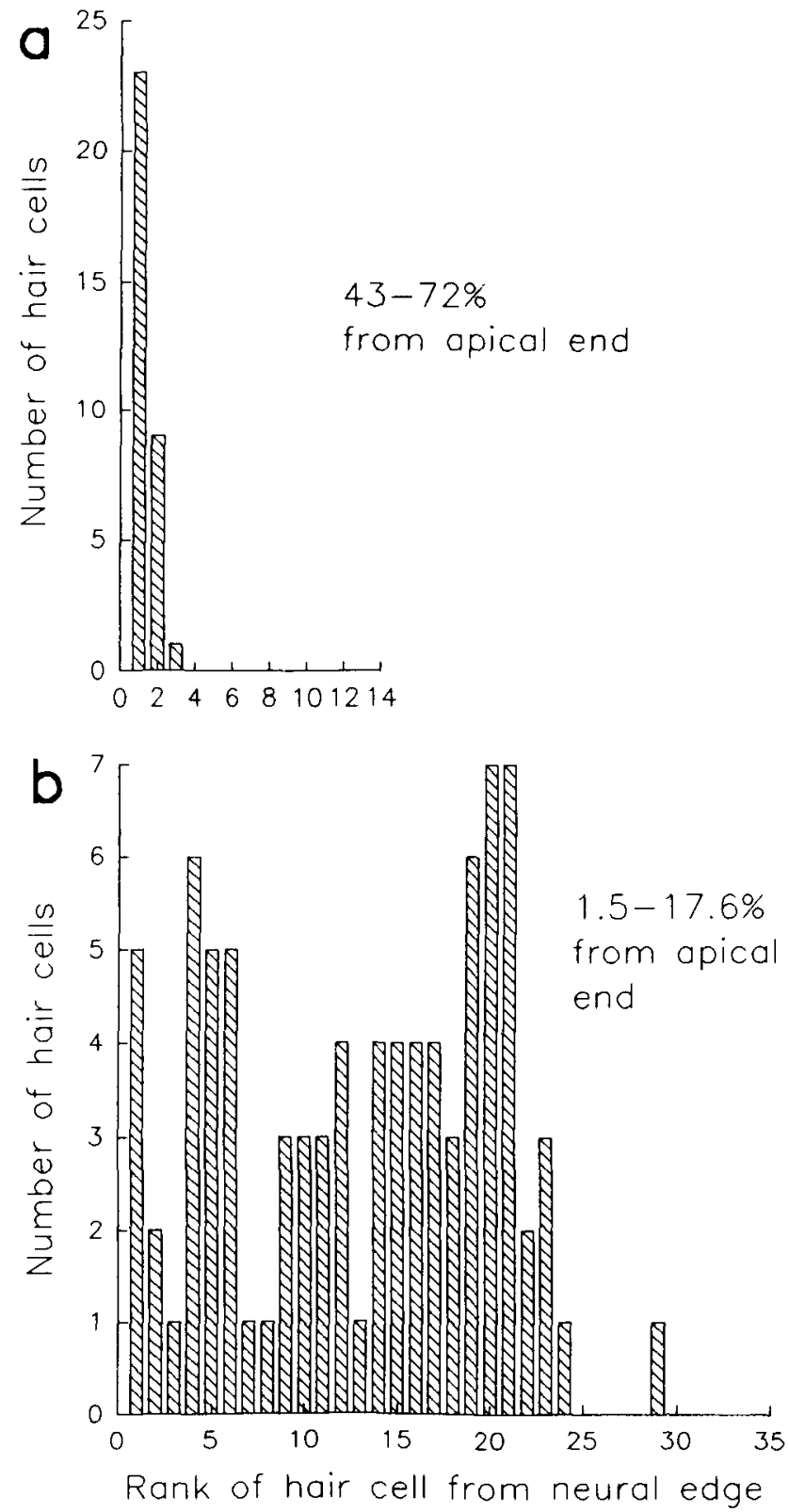

Fig. 9a, b. Position of hair cells contacted by labelled afferent fibres across the width of the basilar papilla. $\mathbf{a}$ and $\mathbf{b}$ show the results of two large HRP-injections into different frequency ranges, with the extent of label along the length of the papilla indicated. The ranges of the abscissae have been adjusted to the average number of hair cells found in one cross section at the respective locations, their scales are, however, identical. In cases, where it was not clear from the sections whether a fibre contacted both or only one of two neighbouring hair cells, both hair cell positions were entered

the lower frequency limit, was set to be $50 \mathrm{~Hz}$ or greater. Without that constraint, the function would be slightly different at the apical end with a y-intercept of $-745 \mathrm{~Hz}$.

\section{Position of innervated hair cells across the basilar papilla}

As described above, the marked primary neurones could not usually be traced up to their synaptic endings on the hair cell(s). However, two large HRP-injections yielded a significant number of fibres with labelled terminals. In both cases, the relevant cochlear areas were sectioned transversally ( $10 \mu \mathrm{m}$ section thickness) to determine the exact location of the hair cells contacted across the width of the papilla.

In a preliminary experiment, not included in the data described above, a very large HRP-injection into NM yielded 26 marked primary fibres contacting hair cells situated between $43 \%$ and $72 \%$ of the length from the apical end of the papilla. Of those, the majority (18) were seen to contact only one hair cell situated at the neural edge. Five fibres terminated between the first and second hair cell from the neural edge, innervating either or both. 3 contacted only the second hair cell from the neural edge and only 1 fibre terminated on the second and/or third hair cell from the neural edge (Fig. 9a). Within this region of the papilla, between about 10 (at the $72 \%$ position) and 18 (at the $43 \%$ position) hair cells are found in one cross section.

Following another fairly large HRP-injection into the low-frequency area of NA, 62 marked fibres could be followed to their target hair cells situated between $1.5 \%$ and $17.6 \%$ from the apical end of the papilla. Within this region of the papilla, about 35 hair cells are found in one cross section. Terminals of marked fibres were identified on hair cells situated anywhere from right at the neural edge up to the 29th hair cell from the neural edge (Fig. 9b). While the majority of fibres (40) contacted only one hair cell, several cases of branching with terminals on up to 4 neighbouring hair cells were also seen. In addition to the cochlear fibres, 3 fibres travelling to the lagenar macula were also marked in that ear.

\section{Discussion}

The frequency map reported here for the barn owl cochlea was derived by labelling small groups of physiologically-characterized primary auditory neurones. This method can be regarded as very reliable, 1 . because the $\mathrm{CF}$ is determined near threshold, reflecting the activity of only a very restricted range of the cochlea and 2 . because the resulting label in the cochlea is also very restricted, reducing the error associated with the necessary definition of a centre. The consistency of our results obtained from labelling neurones of similar CF in different ears (Fig. 7) further supports this claim. In addition, the data cover the whole length of the basilar papilla, and therefore the complete CF-range of the owl, without any significant gaps. We therefore believe that the map is accurate and complete.

\section{The harn owl map in comparison with maps from other birds and from mammals}

Complete or partial frequency mapping data, similar to those reported here, are available for the cat (Liberman 1982), the rat (Müller 1991), the guinea pig (Robertson 1984), two species of bats (Kössl and Vater 1985; Vater 
et al. 1985), the chicken (Manley et al. 1987), the starling (Gleich 1989), the pigeon (Smolders et al. 1990) and two species of lizards (Köppl and Manley 1989, 1990). With the exception of the specialized bats, exponential, power or related regressions have been found to represent the frequency distribution quite well in all those cases. Such a relationship means that the mapping constant, expressed as the length of cochlea devoted to one octave, remains constant or increases slowly from the lowest to the highest frequencies coded. Looking at absolute values, mapping constants in mammalian cochleae are larger than those reported for non-mammalian species: e.g. about $1 \mathrm{~mm} /$ octave (around $0.2 \mathrm{kHz}$ ) to $3.5 \mathrm{~mm} /$ octave (around $40 \mathrm{kHz}$ ) in the cat (Liberman 1982), $0.25 \mathrm{~mm} /$ octave (at $1.2 \mathrm{kHz}$ ) to $2.1 \mathrm{~mm} /$ octave (at $22 \mathrm{kHz}$ ) in the rat (Müller 1991), but $0.1 \mathrm{~mm} /$ octave (below $0.1 \mathrm{kHz}$ ) to $0.6 \mathrm{~mm} /$ octave (extrapolated to about $4 \mathrm{kHz}$ ) in the starling (Gleich 1989), $0.71 \mathrm{~mm} /$ octave in the pigeon (Smolders et al. 1990) and around $0.5 \mathrm{~mm} /$ octave in the chicken (Manley et al. 1987).

Clearly, the barn owl does not conform to this general pattern. Its frequency map is represented well by a thirdorder polynomial, which means there is a dramatic increase in the space devoted to one octave from about $0.35 \mathrm{~mm} /$ octave at $0.3 \mathrm{kHz}$ to $1 \mathrm{~mm} /$ octave around $2 \mathrm{kHz}$ to about $6 \mathrm{~mm}$ for the highest octave $(5-10 \mathrm{kHz})$. Compared to the other bird species, the barn owl cochlea thus provides a similar amount of space for the analysis of the lowest octaves, but an increasingly larger amount for the higher octaves. More than half its basilar papilla is devoted to the frequency range above $5 \mathrm{kHz}$, which is beyond the limit of sensitive hearing in typical birds.

The general shape, although not the absolute mapping constants, of the barn owl's frequency map is comparable to the cochlear maps of highly specialized bats (Kössl and Vater 1985; Vater et al. 1985). Like those mammals, the owl has enormously increased the space available for the analysis of a frequency range particularly important to it. It is known that the high-frequency range between about 4 and $9 \mathrm{kHz}$ provides the most accurate directional cues (Payne 1971; Moiseff 1989) and that the owls rely primarily on these frequencies for localization. In behavioural experiments, for example, they only very reluctantly orient to or strike artificial targets restricted to frequencies below $3-4 \mathrm{kHz}$ and then only with large errors (Payne 1971; Knudsen and Konishi 1979). However, so little is known about cochlear physiology in the barn owl, that the specific contributions of the specialization in the cochlear frequency map to the behaviorally-measured abilities remain to be established.

\section{Correlations with cochlear morphology and physiology}

Studying gradients of a large number of hair-cell parameters (e.g. number of hair cells, dimensions and orientation of their stereovillar bundles, number of stereovilli per bundle) both along and across the papilla, Fischer et al. (1988) concluded that only the apical half of the barn owl papilla showed the gradual changes charac- teristic of the entire papilla of other birds. In the basal half, in contrast, they found most parameters to be remarkably stable. Since morphological hair-cell characteristics such as stereovillar height and number are commonly assumed to influence the local micromechanical frequency response (e.g. Lewis et al. 1985: Patuzzi and Yates 1987; Freeman and Weiss 1990; Manley et al. 1989b), a relative constancy of these parameters correlates well with the slowly-changing frequency representation shown here for the basal half of the papilla.

Physiological correlations of the greatly expanded high-frequency representation on the papilla are less obvious, largely due to a lack of data on the peripheral auditory physiology of the barn owl. The only information presently available is the exceptionally high upper limit for phase-locking in the auditory-nerve spike discharge (Sullivan and Konishi 1984), that forms the basis of the central computation of interaural time differences. It is unclear how this unique phase-locking ability is achieved. However, neural phase-locking in other species seems to be limited by intrinsic properties of the hair cells and/or the afferent synapses (Palmer and Russell 1986; Weiss and Rose 1988), making a contribution of a large space constant on the papilla unlikely.

In bats, the huge increase of space on the basilar papilla for certain small frequency bands is accompanied by a dramatic increase in sharpness of peripheral and central neural tuning in those frequency bands (Suga et al. 1976; Pollak and Bodenhamer 1981; Kössl and Vater 1990). Although data about auditory-nerve tuning are not a vailable in the barn owl, cochlear nucleus cells show neither unusually sharp tuning in the frequency range that can be compared to other birds nor an exceptional increase in tuning sharpness for frequencies above $5 \mathrm{kHz}$ (Sullivan and Konishi 1984; Warchol and Dallos 1990; and our own unpublished observations). Psychophysical experiments with barn owls (Quine and Konishi 1974) indicate that their frequency-discrimination ability lies at the upper end of or is better than that determined in other birds (frequencies 3.5, 7 and $10 \mathrm{kHz}$ tested, Quine and Konishi 1974; Fay 1988). However, the barn owl data are not strictly comparable, since they were derived with an unusual method. In addition, the frequency differences tested were often not followed to the point where the owl's performance fell below the criterion level, leaving the possibility that the true discrimination thresholds were not reached.

\section{Afferent hair-cell innervation pattern}

Bird cochleae show two populations of hair cells, the tall and short hair cells. However, while the typical, extreme forms of those two hair cell types are clearly distinguishable on morphological grounds, tall and short hair cells do grade into each other both across and along the basilar papilla, making any definition of a border arbitrary and dependent on the criteria used (Manley et al. 1989a; Manley 1990; Manley and Gleich 1992). The function of this differentiation of hair-cell shape is currently unclear. Previous studies in starlings, chickens and 
pigeons, using labelling of single primary auditory neurones (Gleich 1989; Manley et al. 1989a; Schermuly and Klinke 1990; Smolders et al. 1992), found that all afferent neurones recorded and labelled contacted only hair cells conforming to the definition of a tall hair cell or only marginally qualifying as a short hair cell according to an arbitrary distinction citerion. Except for the apical end of the papilla, where additional functional specializations for very low frequency ("infrasound") reception are present (Schermuly and Klinke 1990; Gleich 1989), this also meant that labelled afferents were confined to the neural side of the papillar width. Therefore a large population of hair cells exists, situated abneurally and mostly conforming to the criteria of short hair cells, that have not been shown to receive physiologically-active afferents. In addition, analyzing serial TEM sections from the chicken and the starling, Fischer (1992) and Fischer et al. (1992) found that a large proportion of these short hair cells is not contacted by any afferents.

Although in the present study we did not use unambiguous single-cell labelling, the innervation pattern of afferent neurones traced to their hair cells is consistent with the data from other birds, in that the contacted hair cells were confined to the neural side of the papilla. According to the hair-cell classification scheme of Smith et al. (1985) in the barn owl, they lie within areas of tall or intermediate hair cells, sometimes perhaps encroaching on the area of short hair cells. Again, a large population of hair cells, situated abneurally and classified as short by Smith et al. (1985), was not contacted by labelled afferent fibres.

This is an important principle, which thus holds for all birds investigated and strongly suggests different functions for the extremes of the hair-cell forms in birds, perhaps with a gradual transition between both as seen in the anatomy. Indeed, systematic changes in physiological properties (thresholds and tuning sharpness) have been shown in primary fibres innervating hair cells progressively further away from the neural edge of the papilla (Gleich 1989; Smolders et al. 1992). The exact point across the width of the papilla beyond which physiologically-active afferents were not labelled varied along the papilla (Gleich 1989; Manley et al. 1989a; Schermuly and Klinke 1990; Fig. 9) and may, in addition, be different in different bird species, independent of arbitrarilydefined tall-short hair cell borders. Therefore it seems to be of secondary importance whether all hair cells with labelled terminals are tall and all without are short in all species (Smolders et al. 1992).

The definition of hair-cell types and the resulting distribution pattern on the papilla seem to be especially dependent on the criteria in the barn owl. As Smith et al. (1985) pointed out, there are no typical tall hair cells at all in the basal half of the barn-owl papilla. However, these authors defined an intermediate hair-cell population, extending as a narrow neural strip far towards the basal end. It is precisely this small neurally-lying population of hair cells which, in our hands, received stained terminals at the $43-72 \%$ position (from the apical end). Only in the approx. most basal $10 \%$ were purely short hair cells found; these, however, were of a rare sub-type, the lenticular hair cell (Smith et al. 1985). Unfortunately, in the most basal stains, we only found labelled ganglion cells and fibre labelling stopped at the habenula. We assume that these terminated on lenticular hair cells, but we have no information about their position across the width of the papilla. Further studies will be necessary to quantify the hair-cell characteristics and determine the innervation pattern along and across the basilar papilla of the barn owl.

Acknowledgement. This work was supported by the Deutsche Forschungsgemeinschaft within the program of the Sonderforschungsbercich 204 "Gehör".

\section{References}

Carr CE, Konishi M (1990) A circuit for detection of interaural time differences in the brain stem of the barn owl. I Neurosei $10: 3227-3246$

Coles RB, Guppy A (1988) Directional hearing in the barn owl (Tyto alha). J Comp Physiol A 163:117-133

Dooling RJ (1992) Hearing in birds. In: Webster DB. Fay RR. Popper AN (eds) The evolutionary biology of hearing, Springer. New York, pp 545-559

Fay RR (ed) (1988) Hearing in vertebrates: A psychophysics databook. Hill-Fay Associates, Winnetka. Illinois

Fischer FP (1992) Quantitative analysis of the innervation of the chicken basilar papilla. Hearing Res $61: 167-178$

Fischer FP, Köppl C, Manley GA (1988) The basilar papilla of the barn owl Tyto alha: A quantitative morphological SEM analysis. Hearing Res 34:87-102

Fischer FP. Singer I, Miltz C, Manley GA (1992) Morphological gradients in the starling basilar papilla. J Morphol 213:223-240

Freeman DM, Weiss TF (1990) Hydrodynamic analysis of a twodimensional model for micromechanical resonance of freestanding hair bundles. Hearing Res 48:37-68

Gleich O (1989) Auditory primary afferents in the starling: Correlation of function and morphology. Hearing Res 37:255-268

Greenwood DD (1990) A cochlear frequency-position function for several species - 29 years later. J Acoust Soc Am 87: 2592-2605

Knudsen EI, Konishi M (1979) Mechanisms of sound localization in the barn owl (T1\%o alha). J Comp Physiol 133:13-21

Knudsen EI, Blasdel GG, Konishi M (1979) Sound localization by the barn owl ( Tyto alba) measured with the search coil technique. J Comp Physiol 133:1-11

Konishi M (1973) How the owl tracks its prey. Am Sci 61:414 424

Konishi M (1986) How auditory space is encoded in the owl's brain. In: Cohen MJ, Strumwasser F (cds) Communication in the nervous system. John Wiley \& Sons, New York, pp 335-349

Köppl C. Manley GA (1989) An unusual frequency map in the inner ear of European lizards. Abstr 12th Midw Meetg ARO, St Petersburg Bch. Fla, pp 177

Köppl C, Manley GA (1990) Peripheral auditory processing in the bobtail lizard Tiliqua rugosa. II. Tonotopic organization and innervation pattern of the basilar papilla. J Comp Physiol A $167: 101-112$

Kössl M. Vater M (1985) The cochlear frequency map of the mustache bat. Pteronotus parnellii. J Comp Physiol A 157:687-697

Kössl M. Vater M (1990) Resonance phenomena in the cochlea of the mustache bat and their contribution to neuronal response characteristics in the cochlear nucleus. J Comp Physiol A $166: 711.720$

Lewis ER, Leverenz EL, Bialek WS (1985) The vertebrate inner ear. CRC Press. Florida

Liberman MC (1982) The cochlear frequency map for the cat Labeling auditory nerve fibers of known characteristic frequency. J Acoust Soc Am 72:1441 1449 
Manlcy GA (1990) Peripheral hearing mechanisms in reptiles and birds. Springer, Berlin Heidelberg New York

Manley GA, Gleich O (1992) Evolution and specialization of function in the avian auditory periphery. In: Webster DB, Fay RR, Popper AN (eds) The evolutionary biology of hearing. Springer, Berlin Heidelberg New York, pp

Manley GA, Brix J, Kaiser A (1987) Developmental stability of the tonotopic organization of the chick's basilar papilla. Science $237: 655-656$

Manley GA, Gleich O, Kaiser A, Brix J (1989a) Functional differentiation of sensory cells in the avian auditory periphery. J Comp Physiol A 164:289-296

Manlcy GA, Köppl C, Yates GK (1989b) Micromechanical basis of high-frequency tuning in the bobtail lizard. In: Wilson JP, Kemp DT (eds) Cochlear mechanics .. structure, function and models. Plenum Publ Corp, New York, pp 143-151

Moiseff A (1989) Binaural disparity cues available to the barn owl for sound localization. J Comp Physiol A 164:629-636

Müller M (1991) Frequency representation in the rat cochlea. Hearing Res $51: 247-254$

Palmer AR. Russell IJ (1986) Phase-locking in the cochlear nerve of the guinea-pig and its relation to the receptor potential of inner hair-cells. Hearing Res $24: 1-15$

Patuz7i RB. Yates GK (1987) The low frequency response of inner hair cells in the guinea pig cochlea: Implications for fluid coupling and resonance of the stereocilia. Hearing Res 30:83-98

Payne RS (1971) Acoustic location of prey by barn owls ( Tyto alha). J Exp Biol 54:535-573

Pollak GD, Bodenhamer RD (1981) Specialized characteristics of single units in inferior colliculus of mustache bat: Frequency representation, tuning, and discharge patterns. J Neurophysiol $46: 605-620$

Quine DB, Konishi M (1974) Absolute frequency discrimination in the barn owl. J Comp Physiol 93:347-360

Robertson D (1984) Horseradish peroxidase injection of physiologically characterized afferent and efferent neurones in the guinea pig spiral ganglion. Hearing Res 15:113-121
Schermuly L, Klinke R (1990) Origin of infrasound sensitive neurones in the papilla basilaris of the pigeon: An HRP study. Hearing Res 48:69-78

Schwartzkopff J, Winter P (1960) Zur Anatomie der Vogelcochlea unter natürlichen Bedingungen. Biol Zbl 79:607-625

Smith CA. Konishi M. Schuff N (1985) Structure of the barn owl's ( $T_{\mathrm{y}}$ to alha) inner ear. Hearing Res 17:237-247

Smolders JWT, Ding D, Klinke R (1990) Gradients of functional properties of hair cells on the basilar membrane of the pigeon. In: Elsner N, Roth G (eds) Brain - perception - cognition. G Thicme, Stuttgart, New York, pp 125

Smolders JWT. Ding D, Klinke R (1992) Normal tuning curves from primary afferent fibres innervating short and intermediate hair cells in the pigeon ear. In: Cazals Y, Demany L, Horner K (cds) Auditory physiology and perception. Pergamon Press, Oxford, pp 197-204

Suga N, Neuweiler G, Moller J (1976) Peripheral auditory tuning for fine frequency analysis by the CM-FM bat, Rhinolophus ferrumequinum. IV. Properties of peripheral auditory neurons. J Comp Physiol 106: 111-125

Sullivan WE (1985) Classification of response patterns in cochlear nucleus of barn owl: Correlation with functional response properties. J Neurophysiol 53:201-216

Sullivan WE. Konishi M (1984) Segregation of stimulus phase and intensity coding in the cochlear nucleus of the barn owl. J Neurosci 4: 1787-1799

Vater M, Feng AS, Bet7 M (1985) An HR P-study of the frequencyplace map of the horseshoe bat cochlea: Morphological correlates of the sharp tuning to a narrow frequency band. J Comp Physiol A 157:671-686

Warchol ME, Dallos P (1990) Neural coding in the chick cochlear nucleus. I Comp Physiol A 166:721-734

Weiss TF, Rose C (1988) Stages of degradation of timing information in the cochlea: A comparison of hair-cell and nerve-fiber responses in the alligator lizard. Hearing Res 33:167-174 